\title{
Awareness and Utilization of Affordable Medicine Facility-Malaria among Caregivers of Under-Five Children in Ibadan North-West Local Government Area, Oyo State
}

\author{
Ikeoluwapo O. Ajayi, ${ }^{1}$ Tolulope Soyannwo, ${ }^{2}$ and Onoja M. Akpa ${ }^{1}$ \\ ${ }^{1}$ Department of Epidemiology and Medical Statistics, College of Medicine, University of Ibadan, Ibadan, Nigeria \\ ${ }^{2}$ Department of Preventive Medicine and Primary Care, University of Ibadan, Ibadan, Nigeria \\ Correspondence should be addressed to Tolulope Soyannwo; ojot40@yahoo.com
}

Received 19 June 2013; Accepted 14 November 2013

Academic Editor: Polrat Wilairatana

Copyright (C) 2013 Ikeoluwapo O. Ajayi et al. This is an open access article distributed under the Creative Commons Attribution License, which permits unrestricted use, distribution, and reproduction in any medium, provided the original work is properly cited.

\begin{abstract}
Introduction. Distribution of Affordable Medicine Facility-malaria Artemisinin Combination Therapies (AMFm-ACTs) started in Nigeria in 2011, but its use at community level has not been documented. Methods. Four hundred seventy-eight caregivers whose under-five children had fever within two weeks prior to the survey were selected using cluster sampling technique. Information on sociodemographic characteristics, treatment seeking for malaria, and awareness and use of AMFm-ACTs was collected using an interviewer administered questionnaire. Result. More than half of the respondents (51.2\%) bought AMFm-ACTs without prescription. Awareness of AMFm was low as only 9.1\% has heard about the programme. Overall, 29.2\% used AMFm-ACTs as their first line choice of antimalarial drug. On bivariate analysis age, group (25-34 years), public servants, respondents with tertiary education, respondents with high socioeconomic status, respondents with poor knowledge of symptoms of malaria, awareness of AMFm-ACTs, availability of AMFm-ACTs, and sources of drug were significantly associated with utilization of AMFm-ACTs $(P<0.05)$. Logistic regression demonstrated that only people who were aware of AMFM-ACTs predicted its use (AOR: 0.073; CI: 0.032-0.166; $P<0.001)$. Conclusion. Interventions which targeted at raising awareness of AMFm-ACTs among people at risk of malaria are advocated for implementation.
\end{abstract}

\section{Background}

High malaria morbidity and mortality have persisted because of failed transactions between those at risk of malaria infection and available effective antimalarial drugs and preventive measures [1]. Artemisinin-Based Combination Therapies (ACTs), the most effective drugs to treat Plasmodium falciparum, malaria were recommended by World Health Organization (WHO) in 2001 for malaria endemic countries following resistance to the cheap and the long used antimalarials such as chloroquine, sulfadoxine-pyrimethamine, and amodiaquine and the resultant increasing burden of malaria [2]. Since the introduction, distribution of ACT has been slow [2]. Nigeria adopted ACT in 2005 and like the situation in other endemic countries access to ACTs by most people at risk of malaria has been a challenge. The ACTs are not widely used because of their high price, unreliable public sector supply, limited availability in the private sector, and patient self-medication with less expensive monotherapies [3].

In response to the low $\mathrm{ACT}$ access and the threat of artemisinin resistance developing in malaria parasite, the Institute of Medicine released a report in 2004 recommending the creation of a global subsidy (by reducing the price of the drugs at the manufacturer level) and that ACTs be made available through both the public and private sectors at the same price as chloroquine and other common therapies [2]. According to the Institute, the subsidy is expected to expand access to ACTs, crowd out monotherapies, decrease resistance to ACTs, and therefore decrease the burden of malaria. This concept was later developed by the Roll Back Malaria Partnership into a global mechanism known as the Affordable Medicines Facility-malaria. Global Fund hosted the AMFmACTs subsidy project in 2009 [3]. 
Affordable Medicine Facility-malaria-ACTs distribution channels involve both the public and private sectors. The private sector was included because studies done previously indicated that the majority of patients in many malaria endemic countries seek treatment outside of the formal public sector, with a large proportion accessing treatment through the private sector instead. Private sector treatment sources vary considerably between and within countries, ranging from private hospitals and clinics to one-room drug shops, general stores, and medicine peddlers [4]. Studies revealed that patients seek malaria treatment in the private sectorbecause of long distance to, long waiting time at, and stock out of drugs in the public sector as well as shortage of skilled providers [5].

Nigeria was one of the countries selected for AMFm phase 1 distribution. Nigeria started the distribution of AMFm-ACTs in 2011 firstly in the private sector then later in public sector. Society for Family Health (SFH), through the Global Fund Malaria and Prepackaged Therapy (PPT) projects, is working to ensure broad access to ACTs in Nigeria. Through the Global Fund under the AMFm-ACT initiative, SFH is providing a subsidized form of artemetherLumefantrine (AL) known as ACTm. These medicines are distributed through private health care providers including proprietary patent medicine vendors (PPMVs) (local drug shopkeepers) and community-based pharmacies. SFH works closely with the Federal Ministry of Health on technical matters, education, training, and coordinating policy formulation and research to move the nation forward on both prevention and treatment issues in her battle against malaria.

While some effort at studying the adherence of drug distributors to use of AMFm-ACTs has been documented, its use at the community level is yet to be studied. Information on awareness of AMFM-malaria and how it has affected its use is lacking. Several past studies have concentrated on provider's knowledge on the drug and availability of the drugs at facilities where they are distributed. Hence, this study aimed at determining awareness, utilization, and factors influencing utilization of AMFm-ACTs in communities in Ibadan NorthWest Local Government.

\section{Methods}

2.1. Study Area. The study was conducted in Ibadan NorthWest Local Government Area which is one of the eleven LGAs that constitute Ibadan metropolitan area. Ibadan is the capital of Oyo state, one of the 36 states of the Federal Republic of Nigeria. The state is centrally situated in the southwestern part of the country and is $128 \mathrm{~km}$ north-east of Lagos and $345 \mathrm{~km}$ south-west of Abuja, the federal capital territory. For administrative purposes the city is divided into 11 Local Government Areas (LGAs), five of which are urban. Ibadan North-West is one of the five urban LGAs. It has a population of 152,834 people based on 2006 census [6]. The inhabitants of Ibadan North-West LGA are mostly Yoruba while the main occupations of the people are trading and working in the public service. There are 11 political wards and 6 primary health centres (government owned) in the local government [7]. Treatment of malaria takes place in health facilities and at other healthcare providers' places such as private patent medicine shops (PPMVs), pharmacy shops and appointed community medicine distributors. However, home management of malaria using drugs bought from PPMVs and pharmacy is a common practice among caregivers in Nigeria including those in this study LGA.

\subsection{Study Design and Population}

2.2.1. Study Design. This was a cross-sectional study and cluster sampling technique was used in selecting caregivers who participated in the study.

2.2.2. Study Population. Women caregivers in their reproductive age (15-49 years) whose children had fever within two weeks prior to the survey were included in the study. It was estimated that a minimum sample size of 430 caregivers will be required to estimate the true proportion of those using AMFm-ACTs within 5\% precision and assuming a 50\% prevalence of utilization. Four research assistants with Ordinary National Diploma (OND) were trained for two days to assist in data collection. Research assistants were given packets of common antimalarial drugs including that of AMFm-ACTs (also known as antimalarial packet with the green leaf symbol) to show caregivers how to ascertain use of AMFm-ACTs. Data were collected over a period of one month.

2.2.3. Sampling Technique. A cluster sampling of five enumeration areas was done. Based on the information from National Population Commission, Ibadan North-West has 509 enumeration areas [8]. It was estimated that an enumeration area consists of at least five hundred people and women in reproductive age group represent 22 percent of the total population. A total of 110 women were estimated to be found in each enumeration area. From the list of the enumeration areas 5 enumeration areas were randomly selected using table of random numbers. One household was randomly selected by balloting in all the clusters. This household served as the starting point and following a predetermined direction, women of reproductive age in consecutive households in each of the cluster were studied till the allocated sample size of 110 was achieved.

2.3. Data Collection. Participants were interviewed using a pretested semistructured questionnaire. Questionnaire was adapted from ACT watch household survey questionnaires used in seven African countries [9] and questions from the literatures that assessed the utilization of ArtemisininBased Combination Therapy were also added. Questionnaire administration commenced after obtaining approval to conduct the study from Oyo state Ethical Review Committee and after informed consent was obtained from respondents. Information was collected on sociodemographic characteristics, knowledge on symptoms of malaria, treatment seeking for malaria, awareness of AMFm programme, utilization of AMFm-ACTs, and factors influencing utilization of AMFmACTs. 
2.4. Data Analysis. Data were entered, cleaned, and analyzed using Statistical Package for Social Sciences version 15 software [10]. Frequencies, proportions, means, and standard deviations were used to summarize variables. The Chi-square test was used to determine associations between outcome and categorical explanatory variables. Logistic regression analysis was used to determine the predictors of using AMFm-ACTs. The level of statistical significance was set at 0.05 . Use of AMFm-ACTs was defined as use of AMFm-ACTs within 24-48 hours of onset of fever. Information on awareness of AMFm-ACTs was ascertained by asking if the caregivers have heard about AMFm programme, if they have seen the packet of antimalarial drug with the green leaf symbol, sources where AMFm-ACTs was seen or heard, and if they knew what the symbol on the AMFm-ACTs packet meant. Concerning the meaning of the symbol on the drug packet, eight questions were asked and the maximum score that the respondents could get in this domain was 8. Respondents who scored above the mean were taken to have good knowledge and others having scores below the mean were taken to have poor knowledge. Factors influencing use of AMFm-ACTs were considered sociodemographic characteristics, socioeconomic status, awareness of AMFm-ACTs, Access to AMFmACTs, and knowledge on symptoms of malaria. Access was defined in terms of geographical accessibility to drug shops where AMFm-ACTs were being sold and also availability of AMFm-ACTs. Geographical access was considered good if it takes 30 minutes or less (irrespective of mode of transportation) for someone to reach the source of the drug. Socioeconomic status was calculated using the average monthly income of respondents. Respondents were thereafter classified into low and high socioeconomic class using \$2 per day as a cut-off. People of low socioeconomic status were defined as people living below $\$ 2$ per day $[11,12]$. Respondents were categorized as having good knowledge on symptoms of malaria if they have scores above the mean scores, with the total obtainable score based on the number of questions asked and score of the response being 10 marks.

\section{Results}

Four hundred seventy-eight caregivers participated in the study and their characteristics are shown in Table 1. The mean age of the respondents was $31.0 \pm 5.4$ years. Many of the caregivers $287(60.3 \%)$ were between 25 and 34 years, $427(89.3 \%)$ were married, and 287 (60.6\%) were Christians. More than half 293 (61.7\%) of the respondents had secondary education while 267 (55.9\%) were traders and less than half $141(32.2 \%)$ were of high socioeconomic status.

3.1. Knowledge on Symptoms of Malaria. Majority of the caregivers 415 (87.6\%) had good knowledge of the symptoms of malaria in under-five children. Symptoms mentioned were fever 456 (95.6\%), poor appetite $236(49.5 \%)$, vomiting 132 (27.6\%), and headache $83(17.4 \%)$.

3.2. Awareness of Antimalarials and Treatment Pattern. Chloroquine was the most known antimalarial drug 465 (97.3\%) and $312(65.3 \%)$ knew about ACTs. ACTs was mentioned by $203(42.5 \%)$ as the most effective antimalarial. This was
TABLE 1: Sociodemographic characteristics of the respondents.

\begin{tabular}{lcc}
\hline Variable & Frequency & Percentage (\%) \\
\hline Age (yrs) $N=476$ & 58 & 12.2 \\
$15-24$ & 287 & 60.3 \\
$25-34$ & 131 & 27.5 \\
$\geq 35$ & & \\
Income $N=438$ & 297 & 67.8 \\
Low socioeconomic status & 141 & 32.2 \\
High socioeconomic status & & \\
Level of education $N=475$ & 18 & 3.8 \\
None & 107 & 22.5 \\
Primary & 293 & 61.7 \\
Secondary & 57 & 12.0 \\
Postsecondary & & \\
Marital status & 427 & 89.3 \\
Married & 1 & 1.3 \\
Separated & 6 & 0.2 \\
Divorced & 38 & 7.9 \\
Single & 6 & 1.3 \\
Cohabiting & & \\
Occupation $N=478$ & 286.5 \\
Trader & 128 & 5.9 \\
Artisans & 55 & \\
Civil servant & 267 & \\
Others & & \\
Religion $N=472$ & & \\
Christian & & \\
Islam & & \\
\hline
\end{tabular}

${ }^{*}$ Others were housewife, students, and auxiliary nurse.

followed by chloroquine 142 (29.7\%), sulphadoxine-pyrimethamine $103(21.5 \%)$, amodiaquine $19(4.0 \%)$, and Quinine 6 (1.3\%). One hundred seventy-three (36.2\%) knew that ACT was the antimalarial drug recommended by the government for the treatment of malaria.

Most of the respondents 420 (88.8\%) gave their febrile child antimalarial drug, 27 (5.6\%) gave herbs, and 17 (3.6\%) considered the fever not serious enough for the child to be given antimalarial drug. Out of those that gave their child antimalarial drug, $332(79.2 \%)$ did so within 24 hours of onset of fever while $86(20.6 \%)$ responded within 48 hours of onset of fever.

3.3. Awareness on AMFm. Respondents who were aware of AMFm programme were 43 (9.1\%) and less than half 204 $(42.9 \%)$ have seen the antimalarial packet that has the symbol of the Affordable Medicine Facility-malaria. Those who were aware of the programme got the information from diverse sources and the commonest source of information was through the radio 13 (31.7\%). For those who have seen the antimalarial packet that has the AMFm symbol, the commonest place where they saw it was at the pharmacy 125 $(62.8 \%)$. Out of those who have seen the symbol, only $97(47.5 \%)$ had a good knowledge of what the symbol meant. Most of the respondents who mentioned they have 
TABLE 2: Use of Antimalarial drugs.

\begin{tabular}{lcc}
\hline Antimalarial drugs used & Frequency & Percent (\%) \\
\hline Artesunate/amodiaquine & 4 & 1.0 \\
Artesunate & 5 & 1.2 \\
Amodiaquine & 19 & 4.5 \\
Artemether/lumefantrine & 35 & 8.3 \\
Sulphadoxine-pyrimethamine & 112 & 26.6 \\
Chloroquine & 123 & 29.2 \\
AMFm-ACTs & 123 & 29.2 \\
\hline Total & 421 & 100 \\
\hline
\end{tabular}

seen the AMFm symbol 183 (89.7\%) when shown the packet felt it meant nothing, $23(11.3 \%)$ knew it meant subsidized antimalarial drug, and 17 (8.3\%) knew it meant ACT.

3.4. Use of AMFm-ACTs. Overall, 123 (29.2\%) used AMFmACT as their first line antimalarial drug (Table 2). The mean price of the drug was $242.0 \pm 90.39$ which is equivalent to $\$ 1.5$ ( \pm 0.6$)$. Forty-eight (39.7\%) bought it from PPMVs which constituted the commonest source of AMFm-ACTs. About $43(35 \%)$ mentioned that health workers prescribed AMFmACTs, 63 (51.2\%) administered the drug based on selfmedication, and 17 (13.8\%) did so based on recommendation by neighbours, friends, and relations. More than half 67 (54.5\%) cited effectiveness of the drug as the main reason for choosing it while $42(34.1 \%)$ mentioned recommendation by people as a basis for buying the drug. Majority of the respondents $101(82.1 \%)$ reported availability of the antimalarial whenever they go to buy. With regard to geographical access, 93 (89.4\%) had good access to the drugs.

3.5. Factors Influencing AMFm-ACTs Drug Use. Factors influencing AMFm-ACTs use were determined using Chi-square test. Significant factors at 5\% level of significance were put in the logistic regression model. Age group (25-34 years) $(P<$ $0.05)$, public servants $(P<0.001)$, respondents with tertiary education $(P<0.001)$, respondents with high socioeconomic status $(P<0.001)$, respondents with poor knowledge of symptoms of malaria in under-five children $(P<0.05)$, awareness of AMFm-ACTs $(P<0.001)$, availability of AMFm-ACTs $(P<0.001)$, and sources of drug being private clinic $(P<$ $0.001)$ were significantly associated with the use of AMFmACTs. On logistic regression only people who were aware of AMFm-ACTs predicted its use (AOR: 0.073; CI: 0.032-0.166) (Table 3).

\section{Discussion}

The success of Malaria Control Programme hinges on people's awareness of its existence and utilization of interventions provided. Many studies on AMFm have examined the affordability and availability of the drug from the providers' point of view. This study focused basically on the consumers/end users to see if they are aware, if they use the drug and factors influencing their use of the drug. Findings from this study showed that a high proportion of caregivers of children less than five were not aware of the initiative among caregivers of children less than five years. This finding was consistent with a study done in Jos which found that majority of the caregivers were not aware of ArtemisininBased Combination Therapy when it was adopted as the treatment of first choice for uncomplicated malaria [13]. The commonest source of information on AMFm-Acts was the radio. A literature on knowledge, attitudes, and practices about malaria treatment and prevention in Uganda also found radio as the commonest source of information on malaria [14]. The mean price of AMFm-ACTs was $\$ 1.5( \pm 0.6)$. This price is more than the stipulated price for children's dose. Studies have shown that the price at which AMFm-ACTs are sold in some countries that has adopted the initiative was less than the unsubsidized ACTs but more than the government recommended retail price $[3,15]$. For example, a study done in Nigeria and Ghana found the adult dose of AMFm-ACTs to be cheaper than non-AMFm drugs but more than the anticipated price by government [15]. This suggests that the objective of AMFm to increase affordability of the drug has been partly achieved. Although prices are much lower for AMFm-ACTs, research should still be carried out to explore why the drugs are being sold at prices higher than the stipulated government price by drug sellers and other healthcare providers.

An assessment of the use of antimalarial drugs 24-48 hours of onset of fever gave intriguing result. The study showed that a similar proportion of caregivers used chloroquine and AMFm-ACTs as their first line drugs. This is contrary to findings from nationally representative outlet surveys in six sub-Saharan countries in 2011 (Benin, the Democratic Republic of Congo, Madagascar, Nigeria, Uganda, and Zambia) which found that nonartemisinin monotherapies were the most commonly acquired antimalarial drugs for children less than five years of age. The result for Nigeria showed that chloroquine was mostly used [16]. Utilization of chloroquine has been fuelled by its comparatively low price, familiarity of these older products, past successful treatment experiences, and excessive pill burden of artemetherlumefantrine. However, use of AMFm-ACTs can be increased by scaling-up awareness campaign at community level by the government and, non-government organizations involved. There is a possibility of AMFm-ACTs knocking out cheap and long used antimalarials if this is done. This possibility is assumed based on the success of subsidized ACTs that were introduced in Kenya and Uganda [17]. Increased sensitisation about the treatment failure rates and the additional costs that could be incurred due to treatment failure both among health professionals and the community could also help to increase utilization of subsidised ACTs and caregivers desist from using chloroquine and SP [18].

Majority of the caregivers in this study got their drugs from PPMVs. The literature on treatment seeking pattern in sub-Saharan including Nigeria revealed that medicine sellers are widely used as sources of drug for malaria and fever $[19,20]$. Majority of the caregivers reported availability of the drug whenever they go to buy it. This finding is in consonance with a study done in seven African countries in 2012 (Ghana, 
TABLE 3: Logistic regression on predictors of use of AMFm-ACTs.

\begin{tabular}{|c|c|c|c|c|}
\hline Variable & OR & $\begin{array}{c}95 \% \mathrm{CI} \\
\text { lower }\end{array}$ & $\begin{array}{c}95 \% \text { CI } \\
\text { upper }\end{array}$ & $P$ value \\
\hline \multicolumn{5}{|l|}{ Occupation } \\
\hline Trader (Ref.) & 1.000 & & & \\
\hline Artisan & 1.778 & 0.892 & 3.544 & 0.102 \\
\hline Civil servant & 1.861 & 0.321 & 2.312 & 0.767 \\
\hline Others & 1.273 & 0.324 & 4.999 & 0.730 \\
\hline \multicolumn{5}{|l|}{ Source of drug } \\
\hline Supermarket (Ref.) & 1.000 & & & \\
\hline Public facility & 2.094 & 0.223 & 19.653 & 0.518 \\
\hline Private clinic & 5.038 & 0.579 & 43.826 & 0.143 \\
\hline Pharmacy & 1.547 & 0.225 & 10.644 & 0.657 \\
\hline PPMV & 0.505 & 0.077 & 3.325 & 0.478 \\
\hline \multicolumn{5}{|l|}{ Level of education } \\
\hline None (Ref.) & 1.000 & & & \\
\hline Primary & 0.386 & 0.053 & 2.802 & 0.347 \\
\hline Secondary & 0.844 & 0.134 & 5.338 & 0.857 \\
\hline Postsecondary & 1.502 & 0.201 & 11.215 & 0.692 \\
\hline \multicolumn{5}{|l|}{ Knowledge of symbol meaning } \\
\hline Poor & 1.178 & 0.530 & 2.616 & 0.688 \\
\hline Good (Ref.) & 1.000 & & & \\
\hline \multicolumn{5}{|l|}{ Income } \\
\hline Low socioeconomic status & 0.527 & 0.266 & 1.043 & 0.066 \\
\hline High socioeconomic status (Ref.) & 1.000 & & & \\
\hline \multicolumn{5}{|l|}{ Awareness of AMFm-ACTs } \\
\hline No & 0.073 & 0.032 & 0.166 & $0.000^{*}$ \\
\hline Yes (Ref.) & 1.000 & & & \\
\hline \multicolumn{5}{|l|}{ Knowledge on symptoms malaria } \\
\hline Good (Ref.) & 1.000 & & & \\
\hline Poor & 1.817 & 0.734 & 4.498 & 0.196 \\
\hline
\end{tabular}

Kenya, Madagascar, Niger, Nigeria, Uganda, and Tanzania) which found out that there was increase in availability and market share of quality assured ACTs (QAACT) at the PPMVs except for Niger and Madagascar [3]. Another study carried out to determine Artemisinin-Based Combination Therapy availability and use in the private sector of five AMFm phase 1 countries found that market penetration of one or more AMFm QAACT was high both in rural and urban areas [21].

In this study only awareness predicted the use of AMFmACTs. This was similar to a study on insecticides treated net where awareness predicted the ownership and use of the nets [22]. Similarly, in a study in Kenya, community awareness activities were reported to have been instrumental to a substantial increase in ACT availability and coverage [23].

The main limitation of this study was that caregiver's pattern of use of AMFm-ACTs was estimated using caregiver's self-report. Recall bias may likely occur from this, but it was minimized by asking for their pattern of use in the last two weeks prior to the survey.

\section{Conclusions}

Findings from this study revealed that awareness of AMFmACTs was low and this translated to low utilization of AMFmACTs. This may hinder achieving the objectives of AMFm which are to expand access to ACTs. Scaling-up of programmes to increase awareness is needed to increase coverage.

\section{Conflicts of Interests}

The authors declare no conflict of interests.

\section{Acknowledgment}

The authors are grateful to all women who participated in the study. 


\section{References}

[1] D. De Savigny, C. Mayombana, E. Mwageni et al., "Care-seeking patterns for fatal malaria in Tanzania," Malaria Journal, vol. 3, article 27, 2004.

[2] K. J. Arrow, C. Panosian, and H. Gelband, Saving Lives, Buying Time: Economics of Malaria Drugs in an Age of Resistance, The National Academies Press, 2004.

[3] S. Tougher, ACTwatch Group, Y. Ye et al., "Effect of the Affordable Medicines Facility-malaria (AMFm) on the availability, price, and market share of quality-assured artemisinin-based combination therapies in seven countries: a before-and-after analysis of outlet survey data," The Lancet, vol. 380, pp. 19161926, 2012.

[4] S. C. McCombie, "Treatment seeking for malaria: a review of recent research," Social Science \& Medicine, vol. 43, no. 6, pp. 933-945, 1996.

[5] M. W. Hetzel, A. Dillip, C. Lengeler et al., "Malaria treatment in the retail sector: knowledge and practices of drug sellers in rural Tanzania," BMC Public Health, vol. 8, article 157, 2008.

[6] FGN, Federal Republic of Nigeria official gazette, Federal Government Printer, vol. 94, no. 4, 2007.

[7] Ibadan Northwest Local Government, Profile of Ibadan Northwest Local Government, Ibadan, Nigeria, Ibadan Northwest Local Government, 1998.

[8] National Population Commission Ibadan.

[9] ACT watch Nigeria household survey questionnaire, 2009.

[10] http://www-01.ibm.com/software/analytics/spss/.

[11] http://www.worldbank.org.

[12] Rbm AMFm Task Force, "Review of the evidence on access to malaria treatment among the poor in the context of the proposed Affordable Medicines Facility for malaria (AMFm)," 2008.

[13] J. C. Daboer, C. John, A. M. Jamda, M. P. Chingle, and C. Ogbonna, "Knowledge and treatment practices of malaria among mothers and caregivers of children in an urban slum in Jos, Nigeria," Nigerian Journal of Medicine, vol. 19, no. 2, pp. 184-187, 2010.

[14] D. W. Batega, "Knowledge attitudes and practices about Malaria treatment and prevention in Uganda: a literature review," Tech. Rep., Department of Sociology, Makerere University, 2004.

[15] R. Bate, K. Hess, R. Tren et al., "Subsidizing artemisinin-based combination therapies: a preliminary investigation of the Affordable Medicines Facility-malaria," Research and Reports in Tropical Medicine Journal, vol. 3, pp. 1-6, 2012.

[16] M. Littrell, H. Gatakaa, I. Evance et al., "Monitoring fever treatment behaviour and equitable access to effective medicines in the context of initiatives to improve ACT access: baseline results and implications for programming in six African countries," Malaria Journal, vol. 10, article 327, 2011.

[17] M. Schaferhoff and G. Yamey, "Estimating Benchmarks of Success in the Affordable Medicines Facility-malaria (AMFm) Phase 1," 2011.

[18] ACTwatch Group, Outlet Survey Report (Baseline), Nigeria, 2009, http://www.actwatch.info/publications.

[19] C. Goodman, W. Brieger, A. Unwin, A. Mills, S. Meek, and G. Greer, "Medicine sellers and malaria treatment in sub-Saharan Africa: what do they do and how can their practice be improved?" The American Journal of Tropical Medicine and Hygiene, vol. 77, no. 6, pp. 203-218, 2007.
[20] I. O. Ajayi, C. O. Falade, E. A. Bamgboye, A. M. J. Oduola, and O. O. Kale, "Assessment of a treatment guideline to improve home management of malaria in children in rural south-west Nigeria," Malaria Journal, vol. 7, article 24, 2008.

[21] B. Davis, J. Ladner, K. Sams, E. Tekinturhan, Donald de Korte, and J. Saba, "Artemisinin-based combination therapy availability and use in the private sector of five AMFm phase 1 countries," Malaria Journal, vol. 12, no. 1, article 135, 2013.

[22] C. A. Baume and M. C. Marin, "Gains in awareness, ownership and use of insecticide-treated nets in Nigeria, Senegal, Uganda and Zambia," Malaria Journal, vol. 7, article 153, 2008.

[23] S. V. Kedenge, B. P. Kangwana, E. W. Waweru et al., "Understanding the impact of subsidizing artemisinin-based combination therapies (ACTs) in the retail sector-results from Focus Group Discussions in Rural Kenya," PLoS ONE, vol. 8, no. 1, Article ID e54371, 2013. 


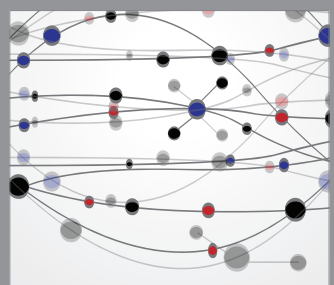

The Scientific World Journal
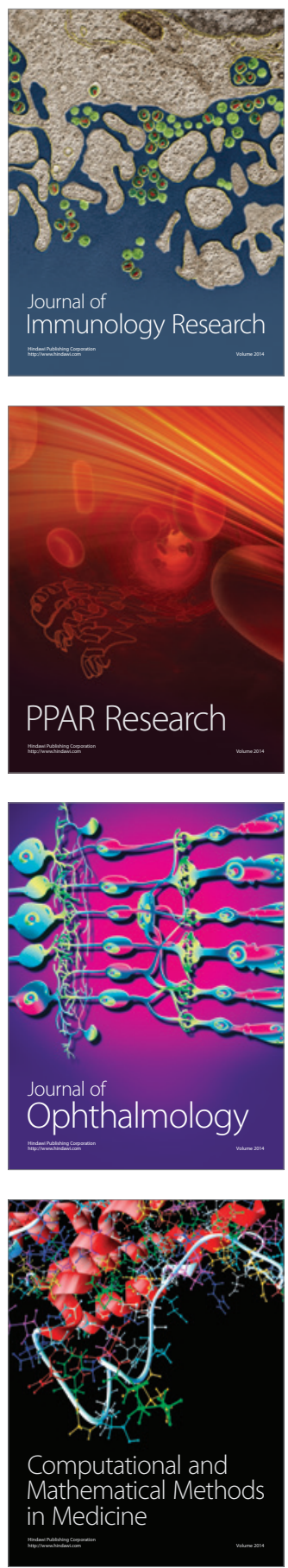

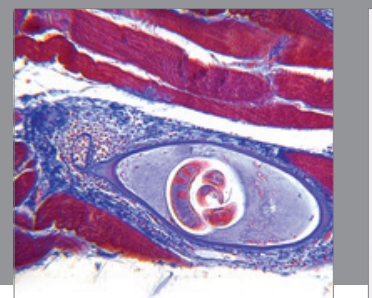

Gastroenterology

Research and Practice
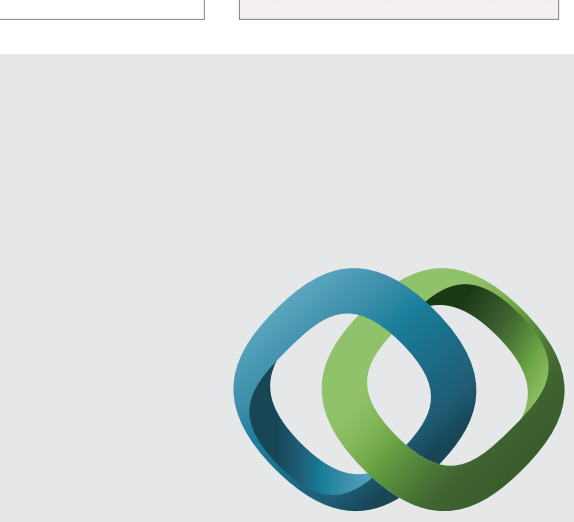

\section{Hindawi}

Submit your manuscripts at

http://www.hindawi.com
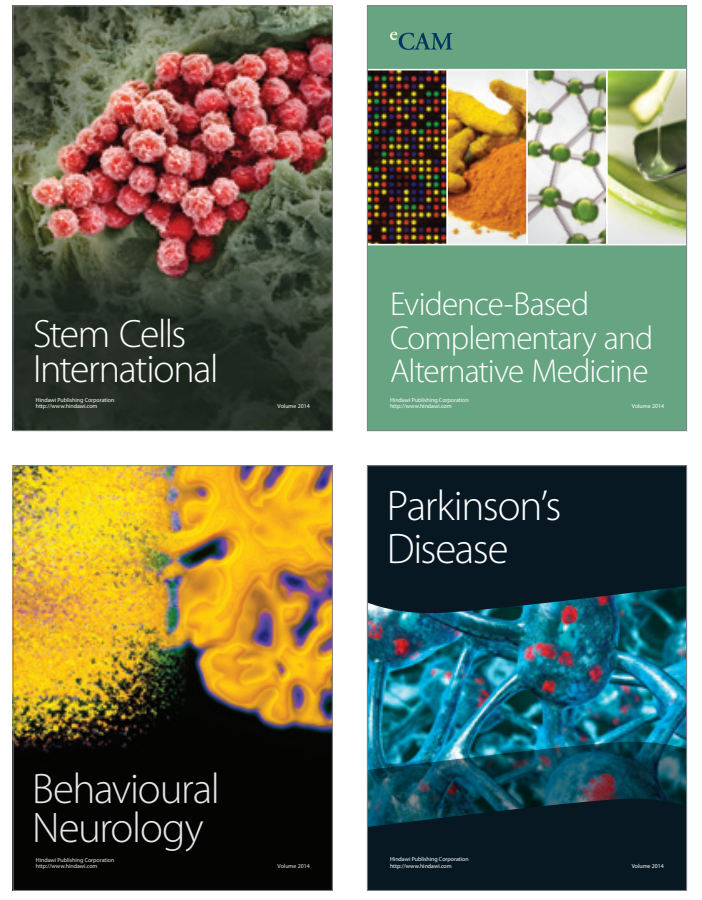
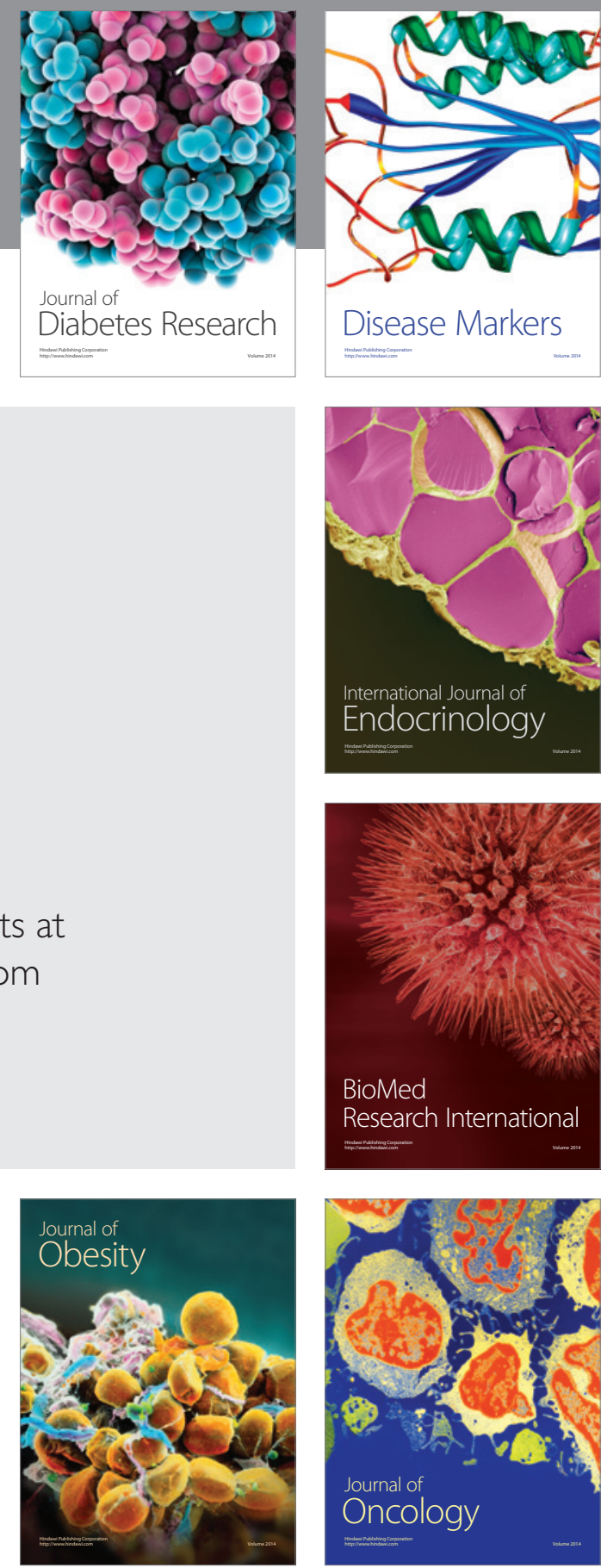

Disease Markers
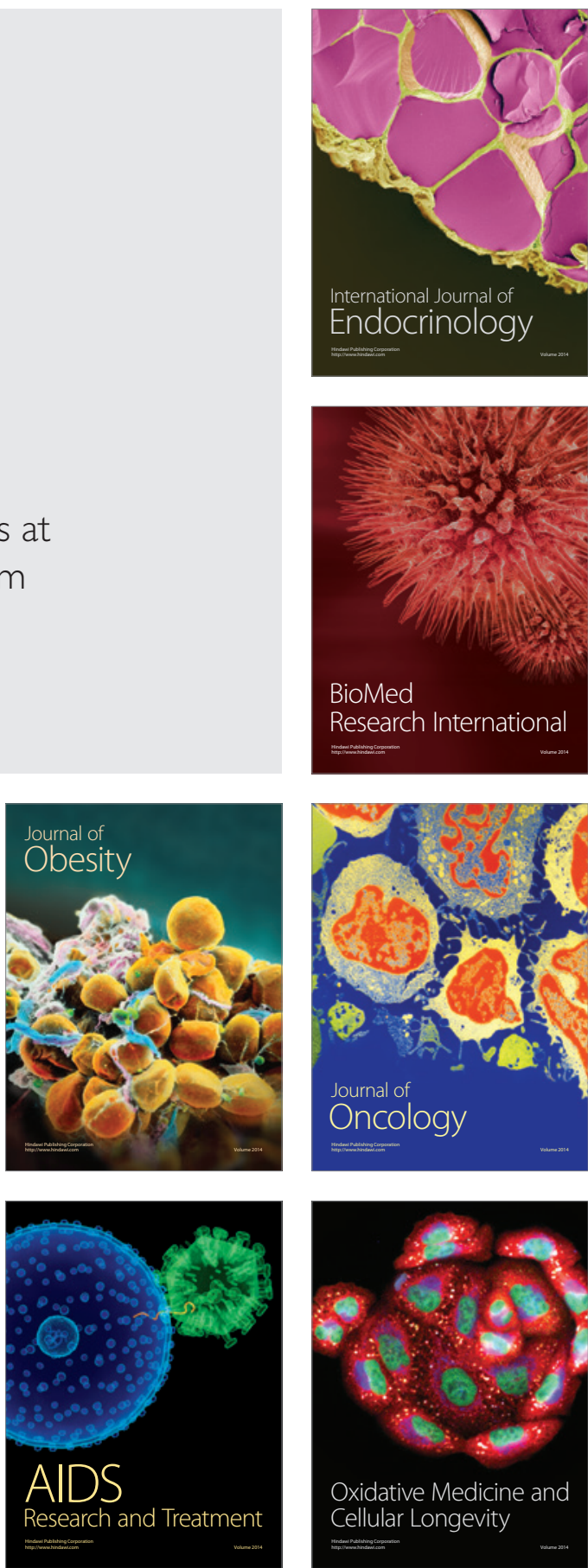